\title{
Benefits and burdens of newborn screening: public understanding and decision-making
}

In this article we review the literature regarding the public understanding of the potential benefits and burdens of expanded newborn bloodspot screening. We draw attention to broadened notions of benefit that go beyond early identification of asymptomatic individuals and interventions to reduce morbidity or mortality, and include benefits gained by families through knowledge that may facilitate life choices, as well as gains generated by avoiding diagnostic delays. We also reflect on burdens such as increasing false-positive results and parental anxiety, together with risks of overdiagnosis when the natural history of a condition is poorly understood. We conclude that expanded notions of benefit and burden bring with them implications for parental consent and confidentiality and the secondary use of bloodspots.

Keywords: anxiety $\bullet$ consent $\bullet$ diagnostic odyssey $\bullet$ knowledge $\bullet$ morbidity $\bullet$ mortality

- overdiagnosis $\bullet$ treatment $\bullet$ uncertainty

\section{Background}

While health examinations have been part of medical care for centuries, the implementation of screening programs has been much more recent [1]. Early identification and intervention for treatable or preventable disease is a key motivator for any population screening program.

Newborn bloodspot screening (NBS) involves taking a small sample of blood from the heel of the newborn and testing it for a number of serious and life-limiting conditions. NBS is the largest and longest running example of population screening [2] and programs are applied across most continents [3-8] with roughly 4 million infants screened annually in the USA alone [9]. The substantial benefits gained by children identified asymptomatically is well documented and NBS was recently recognized by the CDC as one of ten great public health achievements of the last decade [10].

In this review we reflect on the expansion of newborn screening during the recent decades and the debate regarding expanded notions of benefits and burdens that have arisen as a result of increasing technological capabilities to identify underlying biological variation that has hitherto been impossible or impractical. After outlining these debates, we consider in more detail the literature regarding public and parental attitudes to the benefits and burdens of screening, and review how these factors influence individual parental decision-making. We conclude by exploring the gaps in the current literature and speculating on future implications.

\section{Benefits \& burdens of expanded newborn screening}

Many newborn screening programs were established in the latter half of the 20th century - initially testing urine [11] and later progressing to analysis of bloodspots - with a number of bloodspot screening programs arising in the late 1960s and 1970s [12].

Traditionally, screening programs have emphasized the need for a clear understanding of the natural history of a condition together with a clear and immediate benefit to the child [13]. As indicated above, a motivation for NBS is the early identification of
Stuart G Nicholls*,1, Brenda J Wilson', Holly Etchegary², Jamie C Brehaut ${ }^{1,3}$, Beth $\mathrm{K}$ Potter ${ }^{1}$, Robin Hayeems $s^{4,5}$, Pranesh Chakraborty ${ }^{6}$, Jennifer Milburn ${ }^{7}$, Daryl Pullman ${ }^{8}$, Lesley Turner ${ }^{9}$ \& June C Carroll ${ }^{10}$

'Department of Epidemiology \& Community Medicine, University of Ottawa, Ottawa, Ontario, Canada ${ }^{2}$ Clinical Epidemiology, Memorial University, St John's, Newfoundland and Labrador, Canada

${ }^{3}$ Centre for Practice Changing Research, Ottawa Hospital Research Institute,

Ottawa, Ontario, Canada

${ }^{4}$ Hospital for Sick Children Research Institute, Peter Gilgan Centre for Research and Learning, Toronto, Ontario, Canada

${ }^{5}$ Institute of Health Policy Management \& Evaluation, University of Toronto, Canada

${ }^{6}$ Newborn Screening Ontario, Children's Hospital of Eastern Ontario (CHEO), Ottawa, Ontario, Canada

${ }^{7}$ Better Outcomes Registry \& Network (BORN), Children's Hospital of Eastern Ontario (CHEO), Ottawa, Ontario, Canada

${ }^{8}$ Faculty of Medicine, Memorial University, St Johns, Newfoundland \& Labrador, Canada

${ }^{9}$ Eastern Health, St John's, Newfoundland \& Labrador, Canada

${ }^{10}$ Department of Family \& Community Medicine, Mount Sinai Hospital, University of Toronto, Toronto, Canada *Author for correspondence:

Tel: +1 6135625800 ext. 8288

Fax: +1 6135625465

snicholl@uottawa.ca

Future $\because \because$ Medicine part of 
asymptomatic individuals in order to facilitate early intervention with the aim of reducing irreversible damage or mortality. Examples of conditions included within screening panels that meet these criteria include phenylketonuria (PKU), a disorder of protein metabolism that leads to irreversible neurologic damage with severe cognitive impairment when untreated [14,15], or medium-chain acyl-CoA dehydrogenase deficiency (MCADD), which can result in life-threatening episodes that are preventable if the diagnosis is known [16]. In the case of PKU, treatment of affected newborns with early dietary modification can prevent the severe developmental disabilities associated with the condition [14,15]. For MCADD, a delayed diagnosis increases the risk of death or severe morbidity. In both cases detection within the first few days or weeks of life is necessary to maximize the benefit to be gained from treatment.

Since the start of the 21st century there has been a rapid expansion in the number of conditions included within newborn screening programs, particularly in the USA (see Watson et al. for a detailed report on expansion in the US [17] and Botkin et al. for a commentary [18]). Recent additions to screening panels, such as severe combined immune deficiency [19], continue to emphasize the role of prompt identification and intervention for the newborn, yet others less clearly meet established criteria of being amenable to treatment or have been less well characterized with respect to the natural history of the condition, including development from latent to declared disease. As such, a number of recently included, and recently proposed conditions - such as Pompe disease, Fabry disease and Type 1 diabetes [20-25] - have been the subject of debate and evaluation [26].

This expansion has brought with it not only an increase in the number of conditions for which screening is conducted, but also a broadening of disease boundaries and a reformulation of the principles on which screening programs are founded. Some proponents of NBS have argued for an expanded interpretation of benefit on the basis that initial criteria were created for adults and forego the family benefits that may be gained from the knowledge of risk of disease in a child [27]. Others contend that even archetypal cases that are seen as clear examples of the benefit of screening - such as PKU - have not been an unmitigated success $[18,28,29]$, and that only by screening has it been possible to gain a better understanding of the natural history of disease, the variant forms, and therefore improve treatment plans [30]. As such, there has been debate regarding the appropriate application of the original principles and revised criteria have been developed by different bodies and institutions. While these revised criteria retain the original principles of identifying asymptomatic individuals with the aim of early identification to improve outcomes, they also expand the focus beyond the individual to include consideration of the family, or society more broadly, but have also become more specific to the screening program under review, with the inclusion of more detailed assessment criteria [17,31]. Recent attempts have sought to synthesize these emerging criteria (Supplementary Table 1; see online at www.futuremedicine.com/doi/suppl/10.2217/pme.14.46) [32,33]. It is to these expanded and emerging criteria that we turn our attention (Supplementary Table 1).

Recent evaluation criteria employ both an expanded notion of benefit and of the beneficiaries of screening than were common in the earlier screening literature [28]. Both the UK National Screening Committee and the 2006 American College of Medical Genetics and Genomics (ACMG) report include family or societal benefits to differing degrees. In particular, there has been an emphasis placed on psychological and sociological benefits gained from the identification of disease and avoiding the diagnostic odyssey [34-37]. Hence, while NBS has traditionally been based on a 'public health emergency' model, in which early disease identification and urgent action is required to save life or prevent catastrophic morbidity, there has been a shift toward a 'public health service' model [38] in which major additional goals are the provision of information to inform decision-making, reduce the time to clinical diagnosis [34-36] or to provide more moderate interventions to reduce morbidity.

A more contentious connotation of benefit has been the use of reproductive decision-making as a primary justification for expanded screening [39,40]. While the use of newborn screening as a method of gathering information to inform future reproductive decisions has been justified on the basis that clinical diagnosis of an affected child may only occur after a second child is conceived [41,42], this has generally been perceived as a secondary benefit to direct health interventions for the child undergoing screening. Recent studies of healthcare professionals, however, indicate that this view may be changing to emphasize reproductive choice as an outcome $[43,44]$. Bombard and colleagues, for example, note that "providers do indeed perceive the incidental generation of reproductive risk information through NBS as of one its primary benefits" [43]. Indeed this has been reported as an explicit aim within the screening program for Duchenne muscular dystrophy (DMD) in Wales [45]. The suggestion that the provision of reproductive risk should be a primary benefit of newborn screening has caused concern for others $[43,44,46,47]$. In particular, some authors have argued that placing 
reproductive decision-making as a primary goal of newborn screening uses the child as a means for discovering parental reproductive risks, and is unethical [48], transgressing the maxim that individuals should be treated not merely as a means to an end, but as an end in themselves. However, data on the actual use of information in future reproductive decisions, and the benefits that parents derive from such information, is mixed [49,50].

A further implication of citing reproductive choice as a primary benefit of newborn screening is that it lessens the urgency of screening. If informing future reproductive choices is a primary goal, there are options for gaining such information other than newborn screening. It could be derived through parental carrier testing or early childhood screening. When intervention is not time-sensitive, the urgency argument disappears. A corollary of this is that under such nonurgent conditions, and where the primary benefit is to the parent, there is a diminished justification for mandating screening as competent individuals are usually ascribed the freedom and responsibility to make healthcare decisions for themselves.

Expanding the notion of benefit to include familial or social benefits - for example, using newborn screening as a method of generating information regarding the prevalence and natural history of a condition as opposed to having this information a priori - has also generated an implicit expansion of the burdens of screening. Such burdens arise, to some extent, from the inverse of many of the benefits: the production of greater amounts and more complex data brings with it the burden of how best to manage such complexity in ways that promote understanding while minimizing the potential psychological or emotional burden. The generation of data that are potentially useful for population and clinical research generates the burden of managing obligations with respect to privacy, parental understanding and decision-making. Indeed, while early identification and avoidance of the diagnostic odyssey is viewed as an important benefit, managing results, worry and anxiety that may come with an initial screen-positive result are burdens for NBS programs and resource intensive for implicated healthcare providers. With the expansion of newborn screening platforms to include a greater number of diseases or individual assays, and particularly if newborn screening expands to include whole-genome sequencing, there may well be an increase in the number of falsepositive results (for an in depth discussion see Kohane et al. [51]) and a concomitant increase in the associated burdens.

A further implication of the expansion of screening is the potential for results of unknown clinical significance (sometimes referred to as 'overdiagnosis' [52,53] see also Raffle and Gray [11] for a discussion of this with respect to screening programs in general) or overtreatment $[1,53]$. When the natural history of the condition is not well understood, a child may be harmed through overtreatment, especially when the child might never have developed symptoms [54]. A recent case discussion of screening for Krabbe disease illustrates these difficulties [55-57]. Krabbe disease is an inherited, autosomal recessive, neurodegenerative disease caused by a deficiency in a lysosomal enzyme, galactocerebrosidase. Screening for Krabbe disease as part of the NBS program was implemented in New York by executive order. However, in five years of testing only four cases were identified at a cost of US $\$ 3.5$ million. In addition, 20 parents of children were given information as to a potential diagnosis but with uncertainty regarding if, how or when symptoms might appear and what could be done [55]. The treatment involves hematopoietic stem cell transplantation using umbilical cord blood. Although treatment could potentially lead to better outcomes, it is experimental, involves chemotherapy, and presents substantial risks of morbidity and/or mortality [55]. Indeed, the long term impact of treatment, and uncertainty of identifying infant- or adult-onset variant forms, means that some children may be exposed to harms that may outweigh any immediate benefits. Ross [54,58] also cites the example of 2-methylbutyryl-coA dehydrogenase deficiency, a condition that had been diagnosed in only a handful of instances worldwide prior to its addition to the ACMG screening panel. Based on screening results, the identified children were placed on restrictive diets, although subsequently most appeared asymptomatic and it is now believed that the disorder identified is a normal variant $[54,58,59]$.

While the two examples differ in their context: one derives from uncertainty of results from a sought condition, the other an 'incidental' result brought about by the technology used to identify another condition; both represent examples where instigating treatment under uncertainty could have potential harms for the child in question. Aside from the potential for physical harms through restricted diets when variants are benign or invasive treatment, both also have the potential to perpetuate a lack of closure, thus extending parental stress, or anxiety.

In summary, newborn screening programs in the 21st century provide undoubted benefits where early identification of asymptomatic individuals can lead to early interventions that can reduce morbidity or mortality. Moreover, there exist opportunities to provide families with information that may inform future decisions and remove uncertainty where previously a 
diagnosis has been lacking. However, the expansion of screening also brings burdens for both families and newborn screening programs when the natural history of the condition is less well characterized, and where evidence suggests more modest or uncertain clinical benefits. Parents and programs must establish ways of dealing with this uncertainty and develop evidencebased approaches to mitigate the potential harms while continuing to derive the benefits from newborn screening. At a more general level, the balancing of such benefits and burdens and assessment of how they could, and should, be addressed by newborn screening programs needs to remain a focus of discussion.

In the remainder of the paper we consider the existing evidence regarding public - and primarily parental - attitudes toward the identified benefits and burdens of newborn screening, and current understanding of how parents integrate these into their decision-making.

\section{Public attitudes \& understanding of the benefits $\&$ burdens of newborn screening}

While there has been debate as to the appropriateness of screening criteria, the catalyst for much empirical research has been the principle that the test should be acceptable to the population, as presented in the original principles established by the WHO [60]. Consequently, much research has focused on public attitudes toward screening - particularly the inclusion of conditions that do not meet the WHO standards - as well as parental views on the benefits obtained from screening. This body of research tends to indicate that the views of parents, as well as the public, are largely consistent with established criteria, with treatment being first and foremost in parents' minds, with additional benefits being deemed to be secondary to the care of the child.

In qualitative studies undertaken in the USA, parents articulated a greater degree of support for screening for PKU than for DMD [61]. In part the perceived benefits were derived from the interventions available for the child. Findings from The Netherlands concur, where, across four different screening scenarios, 'medical treatment options' were a frequently mentioned benefit [62]. Similarly, focus groups with parents in the USA identified medical treatment as the most consistently mentioned benefit of newborn screening, although early identification of disease in the absence of curative therapies was still seen as a benefit [63].

Other studies have reflected the expansive notion of benefit in terms of moving from medical treatment to broader consideration of interventions, while retaining a primary focus on the benefits to the child. Hasegawa et al., for example, note that parents in the USA supported newborn screening for 'untreatable dis- orders' on the basis that the information would facilitate families and healthcare professionals assisting the child through earlier diagnosis and interventions to improve care [64]. Other studies across different jurisdictions have generated similar results, with the public supportive of newborn screening for directly treatable disorders, but also conditions where benefits may be through interventions to prepare for any special needs required by their child [65-70]. These studies tend to replicate professional debates with recurring themes of the risk to the newborn, utility of the information generated, and potential for preparation or to inform future reproductive choices [71]. One explanation for this high level of support may be a general inclination to promote beneficence: the potential to screen children and generate information that could improve health, either through access to treatment or services, is viewed as valuable [72]. An important caveat is that in many cases, those interviewed or surveyed have not experienced newborn screening (as a parent) or have only experienced a screen-negative result, and it may be that experiences of false- or true-positive results provide a different perspective. This is reflected somewhat in research with parents whose children were diagnosed with cystic fibrosis and where their experiences and attitudes reflected both the benefit - clinical interventions together with relief from uncertainty generated by receiving a diagnosis - as well as potential harms when such a diagnosis is unexpected [73]. As such, screening experiences are a balance of benefits and burdens.

A body of research is now emerging on the management of information regarding newborn screening and parental responses to screening results. Specifically, great attention has been paid to how any potential negative effects can be mitigated [49,74-76], and the potential negative implications associated with false-positive results, such as parental distress or impaired parent child bonding [35,76-79]. Studies of responses to screenpositive results indicate that while many parents do not suffer substantial long term ill effects, some parents may exhibit anxiety, distress or worry [35,75-80], which may in turn lead to hypervigilance [49], although other studies point to no differences in parental stress between parents receiving information regarding risk and those serving as controls [81]. Grob, for example, recounts one mother's experience with a positive screen for cystic fibrosis, after which she recalls calling the hospital multiple times whenever her child appeared to be breathing heavily [73]. For families who receive an initial screen positive result that is later dismissed following diagnostic testing - a 'false-positive' - studies have indicated that mothers have higher levels of stress compared with those mothers of children who receive a negative screen [74,75], again potentially leading to hypervigilance and 
overprotectiveness [74]. These results are likely transient in the majority of cases [82,83], although a systematic review of the effects of disclosing carrier status suggests that concerns may persist in a minority of parents even when diagnostic testing has confirmed that their child is not affected but a carrier [49].

Several studies point to steps that can be taken proactively, and indicate that education and improvement in parental understanding may mitigate some of the psychosocial harms [74,84]. This can be further facilitated by the approach to information delivery, with a consistent finding being that parents express a preference for information in the prenatal as opposed to the immediate postnatal period [85-88].

A particularly burdensome aspect of information management for both parents and newborn screening programs arises when initial results are not be clarified by diagnostic testing. In their USA-based research, Timmermans and Buchbinder note, for example, that while the vast majority of parents who receive an initial screen-positive result will present for further diagnostic testing that reveals the result to be a false positive, and a small percentage will be true positives, a number will receive a result of uncertain clinical significance [89]. This, they argue, has led to a population of 'patients-inwaiting' where, rather than preventing the diagnostic odyssey, expanded screening has created a situation of diagnostic uncertainty in which there is both biological and social ambiguity - the clinical significance of the results is not established nor are the actions required on the part of the family [89]. These authors also noted that parents reported concerns about bonding with their child for fear of compounding their grief should the child become sick or die $[89,90]$.

This, it is argued, is partly facilitated by contradictory messages from physicians and specialists: the conditions are rare and thus a high proportion of positive results are false positive, and so in effort to avoid creating undue anxiety, clinicians may tend to be reassuring about the probability that the child is affected; while at the same time they urgently advise diagnostic evaluation. In the event that diagnostic results are uninformative (i.e., disease cannot be ruled in nor out), these messages about low probability yet urgent testing are hard to reconcile so that it is challenging for families to evaluate the degree of risk for their child. This has been noted with respect to the initial presentation of screening in which parental concern is tempered yet the importance of screening is emphasized, something Nicholls has referred to as the 'dualistic representation' of newborn screening [72].

In each of these examples, the burden relates to the management of information - by both parents and newborn screening programs - and expectations as well as parental understanding of the meaning of screening results. This has been referred to as the burdensome nature of knowledge [39] or the communicative burden [91], and despite ongoing research regarding approaches to mitigate potential psychosocial harms, there remains a substantial knowledge gap in how best to provide initial information to parents and a need to establish an evidence-base for informing parents about newborn screening [92].

\section{Benefits, burdens \& consent processes}

The rationale for mandated screening is often predicated on the serious and preventable nature of the diseases, by concerns regarding feasibility or costs, or by concerns regarding parental refusal based on misconception $[1,91,93]$. The expansion of screening in some jurisdictions to include conditions where both natural history and clinical intervention have been less well characterized, together with an increased emphasis on information provision as a benefit of newborn screening, has prompted renewed discussion about consent processes for NBS [18,42,58,61,71,94-97]. At one end of the spectrum are programs where non-participation is essentially not an option: for example, most newborn screening programs in the USA are officially mandated, although in most states parents may refuse for personal or religious reasons $[54,98,99]$. This position has been supported by several professional bodies [99,100]. In the US state of Nebraska, for example, screening is mandatory without exception [101,102]. In other states, while parents are able to opt-out, studies indicate that often parents are not afforded the opportunity to consent or are poorly informed about the opt-out option [9]. At the other end of the spectrum lie jurisdictions, such as the $\mathrm{UK}$, in which screening is offered explicitly on a choice basis [103]. In a number of Canadian jurisdictions, screening is presented as standard of care with the view taken that screening occurs by default unless there is a specific objection by the parents [104-106].

In part, concerns regarding feasibility may depend on how practitioners conceive of consent and the requirements that this would impose [106]. Miller et al. note that while some healthcare professionals felt that informed consent for newborn screening was not practical "[...] because you'd have to go into a discussion about every single disease that you can test for and every single result you can possibly get" others indicated a less complex view of the requirements to obtain informed consent and that "it's not time-consuming to do and people get it" [106].

Empirical data also suggest that concerns regarding increased refusal rates under voluntary programs appear to be unfounded. Uptake of NBS is consistently found to be almost universal [45,88,98,107-109]. Even with optional 
screening programs, for conditions such as DMD, and less predictive screening tests (such as Type 1 diabetes), uptake rates have been found to be consistently high with 94-95 and 94\%, respectively [45,61]. A recent UK study that sought to evaluate models of decisionmaking found that increases in perceived choice - that parents felt a choice was available and they were able to make a choice - were positively and strongly associated with greater perceived knowledge of screening and indirectly with more positive attitudes toward screening. Both more positive attitudes toward screening and increased perception of choice were significantly associated with less conflict in decision-making [110]. As such, rather than increasing the potential for ill-informed refusals, facilitating a perception of choice may in fact evoke more positive attitudes toward screening and improved decision-making while potentially improving understanding.

\section{Parental knowledge \& understanding: implications for consent approaches}

Despite the apparent success of newborn screening, some authors have questioned whether such high uptake rates in voluntary programs reflect informed consent on the part of the parents, or a routinization of screening [111,112], particularly in the context of less well-characterized conditions or where there is a lack of efficacious treatment. Several studies have sought to address this concern by exploring parental understanding as a prerequisite for parental consent or by assessing parents' awareness of choice and involvement in decision-making.

The assessment of parental understanding of NBS has largely been through knowledge assessment based on the accurate recall of information. Research in this area tends to suggest a latent awareness of the motivation for screening and how it will be conducted [104,113], but a low level of specific knowledge regarding how screen-positive results will be dealt with, the names of conditions, or their major cause [64,108,114-117].

Most worryingly, some parents do not have an awareness of the screening program [118,119], and others do not know whether their own child has been screened [61,88]. In an Australian study with women who had received written and oral information, only 37\% recognized the term 'Guthrie test' (a common colloquialism for newborn screening), 'heel prick test' or 'newborn screen'. Moreover, while $40.5 \%$ of mothers stated that their child had not undergone the test, records revealed that only $2 \%$ of infants had not actually undergone the test [120]. Given the State operated under a principle of 'informed dissent', this finding is somewhat disconcerting.

An important qualification, however, is that knowledge - assessed by recall of information - may be distinguishable from understanding, the latter more relevant to concerns regarding parental consent [121]. The correct recall of information may in fact belie a lack of understanding. For example, in a study in The Netherlands, Detmar and colleagues noted that, while participants recognized key terminology, they tended to do so without comprehension as to the purpose of the heel prick [87]. Consequently, asking parents to recall specific pieces of information does not specifically reveal whether information - such as the implications of screening - are understood. An older USA-based study found that while parents of children with hemoglobinopathies had been given - and could recall - the recurrence risk for future children, the majority could not explain what they had been told. As such, they may be viewed to be knowledgeable, if knowledge is assessed purely by recall of information, but the inability to explain this demonstrates a lack of understanding as to the meaning of the information [122]. Both of these examples indicate that parents' ability to recall specific information - such as recurrence risks - may not reflect an understanding as to the implications of disease or motivation for screening, both of which may be more salient and important with respect to maximizing the health of their child [121].

\section{Screening uptake \& perceptions of choice}

One potential explanation for the high levels of uptake may be that the outwardly promoted requirement of parental decision-making - be this through an opt-out informed dissent process or opt-in informed consent model - is experienced by parents as institutional rhetoric'. This supposition finds support in findings that parents experience screening as routine and not a choice [114]. Studies in the UK are particularly illustrative here as newborn screening is ostensibly provided on the basis of an informed choice [123], where parents have been shown to view newborn screening as routine [124] and a 'fait accompli' [15]. In a Welsh study it was found that, when a second card for an optional screen for DMD was introduced, it led to a significant increase in parental awareness that the test was optional. Despite this, $15 \%$ of those involved in the intervention arm did not realize the test was optional and a small minority felt that they did not have a choice, despite the explicit nature in which it was provided. This led the authors to conclude that: "It would seem that, although the majority of mothers felt they were being given a choice about screening, for some it was a choice about a test they thought was always done. This, in reality, is no choice at all" [125]. In a more recent UK study Nicholls and Southern noted that parents talked about the 'proceduralization' of screening: the structure of the healthcare system meant 
that one process led to another creating the perception that screening was just part of a larger system of care that is initiated following the birth of the child [126]. However, examples of routinization are not restricted to the UK. Research in The Netherlands regarding parental experiences of screening for congenital hypothyroidism found that most parents saw screening "as a routine business that no one ever hears about again, and that people do not give much thought to" [127]. In a further study in The Netherlands, Detmar et al. [87] noted the same routinized attitude. Other studies have noted that parents even reported that the taking of blood for analysis was conducted in their absence, obliterating any notion of informed consent [84,127].

Notwithstanding these findings, there is evidence that at least some parents welcome a recommendation from a healthcare professional. Australian research has found that, while some parents felt that they had not given a specific consent, most were unconcerned by this [128]. UK research suggests that parents are happy to accept a routine screen that is recommended by their midwife, with some parents commenting that "If they had been offered a choice, many said they would have opted for their child to be screened" [114]. As a result, the mere offer of a screening test may result in a sequence of events that, under the prevailing social norms, means that one's actual experience of 'choice' is that there is no choice at all. Thus the ability to provide an informed consent is not merely about having the facts to make a rational choice. The findings that parents do not necessarily experience a choice may also indicate more subtle pressures are being exerted, such as the way that the screening tests are offered, the information that is provided and the institutions or individuals that provide them.

Consent has been raised as a subject more recently within the additional context of the secondary use of residual bloodspots. These samples may be stored for years for the purpose of repeat testing, quality control, or testing as part of diagnosis [9]. However, they may also be used for purposes beyond the screening program, including external quality assurance and research, or for investigative purposes: for example, in The Netherlands it was proposed that residual bloodspot samples could be used to assist with forensic analysis following an explosion at a fireworks factory $[129,130]$. Concerns over privacy have led to several high profile legal cases and media interest in the US $[67,116,129,131-133]$ and ultimately changes in storage policy and the destruction of millions of dried bloodspot samples [132].

Concerns regarding the storage of samples have featured in discussions about public attitudes toward screening, often linked to questions of consent and whether parents should provide explicit consent for storage of residual bloodspots. These reported concerns range from treating children as research 'guinea pigs' and the type of research undertaken, to general concerns regarding the lack of awareness about research on samples $[61,67,134]$. However, despite the general lack of awareness [104], when prompted, parents and the public tend to be supportive of medical research using these bloodspots, often with the caveat that they are de-identified and steps are taken to protect privacy [67,134-136]. As with attitudes toward screening in general, when the goals of research are for the primary benefit of the child or families affected by the conditions for which research is undertaken, then support is generally stronger than the use by for-profit organizations, or in nonhealth-related contexts such as criminal investigations [67]. Irrespective, parents tend to indicate a preference for informed consent approaches [136].

\section{Benefits, burdens \& individual \\ decision-making}

Despite the research regarding public attitudes toward the benefits and burdens of screening, their understanding of screening and experiences of consent approaches for screening, these studies in and of themselves tell us little about individual parental decisions. In this regard there is a much thinner evidence base. Studies of parental decision-making suggest a dominant factor is the perceived benefit of screening. However, these perceptions are informed by more general attitudes towards medicine.

Studies support the use of broader notions of benefit in parental decision-making, and specifically the role that information obtained from screening can provide with respect to empowerment. Parsons et al. [137], for example, noted that the majority of reasons given by parents for accepting screening for DMD related to themes of gathering knowledge. As with the attitudes expressed by parents towards newborn screening, much of this knowledge-seeking was related to benefiting the health of the baby through better knowledge of the condition, time to prepare, and the ability to get early help [137]. This is not to say that all parents want the screening results. In the same study, a cited factor for declining screening was the desire not to know. Thus knowledge may be central to decision-making, but not deterministic of the direction of the decision.

This is evidenced by parental discussions of scenarios, such as screening for DMD, in which some parents suggested they would refuse screening because of the lack of benefits, broadly construed [61,137]. This is clearly illustrated in the response of one mother in a UK study who regretted having a screening test for DMD and who indicated she would have refused had 
she known that the disease was untreatable [138]. In one of the few studies to actually explore parental decisions, researchers, again in Wales, UK, found that the majority of parents who declined newborn screening for DMD on the basis of 'disease detection' reasons offered the argument that the lack of a cure was a factor in their decision to decline [137]. The finding that the health of the child is regularly invoked as the main reason for having the screening is not only consistent with the original principles on which newborn screening was based [60], but is also in line with the moral principle of beneficence. This moral position appears to guide parents when weighing the potential risks and benefits of screening, with a willingness to accept some harms if they are outweighed by the benefits. As parents in one study put it: "[...] But when she's born, I'd rather know if there was anything wrong with her to try and treat her" [72]. Thus the perceived health benefit, or potential health benefits, brought about by NBS are instrumental not only for their support for the screening program generally, but also for their own decisions to have their child(ren) screened.

Several studies suggest that these specific attitudes are mediated by the parents' general attitudes towards medicine. For example, parents who offered reasons why they accepted newborn screening for DMD, did so due to a belief in research, support of screening in general and the simplicity of the test [137]. For those who refused, a wish to avoid medical intervention and a perception that the test would not aid research were also given. This association between general attitudes towards medicine and specific attitudes toward screening - and subsequent influence on decisionmaking - has been explicitly noted in subsequent studies. Nicholls and Southern found that positive general attitudes toward medicine were significantly associated with more positive attitudes toward screening specifically [110].

These general and specific attitudes may be a direct result of parents' own experiences or those of a trusted acquaintance [72]. A further study from the UK noted that some parents refused screening because they actively avoided medical input, and that one family refused because they thought that the screening test was a barbaric procedure based on the experience of an acquaintance [139]. In part this may be mediated by the role of the parent-healthcare professional relationship, as noted by Parsons et al. [115] and Muchamore et al. [67]. In both studies trust in the midwife or healthcare professionals was an important factor in parental decisionmaking, even overriding the need for information in some parents [115]. Nicholls and Southern suggest that the provision of screening on a population-wide scale by a trusted healthcare professional may be seen to imply that screening is beneficial. In a context of healthcare rationing where some treatments were funded and others not, the wholesale provision and support for newborn screening indicated to parents that a process of evaluation and decision-making had taken place, and the provision of screening indicated its worthwhileness [72]. Trust in the medical profession may, therefore, be a causal element in determining that screening is beneficial, due to the fact that screening is offered by the medical community. These findings signal the importance of trust in the system of governance for screening programs and why researchers and practitioners must be mindful of how issues such as the secondary usage of residual bloodspots may play into attitudes toward screening programs and, ultimately, uptake.

The role of trust in individual decision-making may also help inform our understanding of perceptions of choice for newborn screening. If screening is offered by a trusted source, this may be taken by parents as evidence to imply that screening is beneficial. If testing is perceived to be beneficial, it may also be perceived that there is no choice to be made: if one has already established that conveying benefit to the child is the correct moral position, and screening conveys a net benefit, then screening is the correct choice. It is not a preference-sensitive decision.

\section{Where are we, what do we still need to learn \& why?}

Despite research indicating parental support for screening, and variation in parental knowledge and understanding of different aspects of newborn screening, there is still a paucity of research regarding the determinants of parent understanding and factors that influence individual decisions. Most notably, we know very little about why some parents decline newborn screening and whether these parents differ in some substantial way from those who accept screening. There is, however, burgeoning research that points to broader influences on parental decisions; research that may point to systemic differences.

In Canada, a recent review by Newborn Screening Ontario revealed that uptake of NBS is extremely high, but that the majority of active 'declines' came from parents under the care of midwives [140]. These descriptive data point to the need for more research on the relationship between professional and parent attitudes and experiences in relation to consent practices for NBS. For instance, do individuals who choose midwifery care have different attitudes toward screening than those who choose obstetricians for their prenatal care? Do midwives have substantially different opinions to other healthcare professionals? Are there system-level issues in play that somehow generate these differences? 
There is a need for educational research regarding NBS, in relation both to parents and professionals. In a Canadian study by Hayeems et al., different healthcare providers reported differing views with respect to their own role in the education of parents, as well as barriers to informing parents [141]. Notably, the majority of family physician respondents and obstetricians indicated they had insufficient training to educate parents, while over half of these same groups agreed to some degree that they were not up to date on the conditions being screened and that they lacked confidence in their ability to explain newborn screening to parents.

While research has, understandably, focused on parents and healthcare professionals in relation to newborn screening, a third - and yet unstudied - stakeholder group also exists and warrants further study: those involved in policy development. While the exemption of policy makers might reflect the fact that they are seemingly far removed from the clinical encounter [142], if policy decisions are incongruent with clinical routines, then parents may suffer through inconsistent practice. Indeed, given the jurisdictional variations in newborn screening consent models, it is important to explore the rationale behind screening policy decisions to identify areas of commonality and difference. At present, no research has explored the perspectives of policy decision-makers with respect to consent processes for newborn screening and the implications for professional practice or parent understanding.

Furthermore, while there has been increasing debate about criteria for expanded screening leading to broader definitions of benefit, far less attention has been paid to how burdens of newborn screening should weigh into these equations and how programs should seek to balance the potential burdens with the benefits offered. Moreover, there are a lack of criteria for decision-making around the exclusion or removal of conditions within existing panels (although processes are currently under review [143]). Recent discussion in the field of implementation science has explicitly raised this issue and called for greater exploration of issues pertaining to the deimplementation of technologies [144]. This is highly relevant given the experiences with screening for Krabbe disease in New York, and which underline the need for the development and evaluation of de-implementation criteria [55-57,145].

Concerns regarding overdiagnosis also require further consideration. For example, diagnostic testing may be unable to confirm whether a baby has cystic fibrosis when the significance of an identified mutation is unclear and sweat testing is borderline. Does this differ to the situation where diagnostic testing establishes the targeted disease but where it is uncertain whether the baby is at risk of developing the clinical phenotype because it is so clinically heterogeneous and/or dependent on environmental conditions (e.g., 'non-classic' cases of MCADD)? In both cases there are different facets of overdiagnosis that present similar challenges for families, but require different solutions from the perspective of providing care, changing the screening program, or mitigating harms.

Questions of how benefits and burdens should be balanced will be even more pertinent given the potential for whole-exome or whole-genome sequencing (WES/WGS) within newborn screening programs $[146,147]$. Given current concerns regarding variants of uncertain clinical significance, analytic and clinical validity will be hugely important. How well does sequencing measure the intended target? What is the accuracy with which sequencing predicts the presence, absence or predisposition to a condition [148]? A recent study found substantial differences between sequencing platforms $[149,150]$ and several studies point to a lack of understanding with respect to the interpretability of WES/WGS information [151,152]. Yet even if the implications of variants are understood, significant practical issues of data management and communication remain. Feero, for example, notes that a recent sequencing study identified approximately three million unique variants per individual who underwent sequencing [150]. Each variant required collating, tracking, analyzing and then communicating. The possibility of vast amounts of information, including cumulative risks derived from multiple low-penetrance variants, potentially expands definitions of the meaning of an asymptomatic individual, but may also exacerbate existing issues such as anxiety and stress, especially if parents do not feel informed or do not understand newborn screening [74-77]. There is a need for ongoing research to explore the potential for inequitable experiences of newborn screening and the development of evidence-based communication strategies that seek to mitigate the potential for negative psychological sequelae. These communication approaches will require ongoing evaluation and will remain an important area of research as newborn screening moves forward.

\section{Conclusion \& future perspective}

The continued advancement of screening technology is likely to lead to the incorporation of WES or even WGS within newborn screening programs. The management of information generated by these technologies will likely be a focus of research and practice for the foreseeable future. We suspect that wholesale use of genome-level information will remain a promissory goal, but that barriers related to the capacity of healthcare systems - cost, data management, and clinical expertise - as well as patient limitations with respect 
to the amount of information that can be absorbed, will require the consolidation of information into packages, bins, or other more manageable forms. The practicalities of information management will influence the application of these technologies. We anticipate a concomitant move away from onerous specific consent approaches in which processes and results are provided in intimate detail, to more generic or broad consent approaches grounded in the types of information or general uses to which information and samples will be put.

Financial \& competing interests disclosure

This work was supported by funding from the Canadian Institutes of Health Research (CIHR) (EOG-131589). SG Nicholls is supported by a CIHR Postdoctoral Fellowship (Ref: 122403). The authors have no other relevant affiliations or financial involvement with any organization or entity with a financial interest in or financial conflict with the subject matter or materials discussed in the manuscript apart from those disclosed.

No writing assistance was utilized in the production of this manuscript.

\section{Open Access}

This work is licensed under the Creative Commons Attribution-NonCommercial 3.0 Unported License. To view a copy of this license, visit http://creativecommons.org/licenses/bync-nd/3.0

\section{Executive summary}

\section{Background}

- Expanded screening has led to discussion of expanded notions of benefit and burdens.

Benefits \& burdens of expanded newborn screening

- Benefits include early intervention with resultant reduction in morbidity and mortality, knowledge gained from the identification of disease, and avoiding diagnostic delays.

- Burdens include potential for anxiety, a lack of confirmatory diagnosis, overdiagnosis and overtreatment.

Public attitudes \& understanding of the benefits \& burdens of newborn screening

- Public attitudes largely reflect professional and academic debates, with an emphasis on support for programs where the primary benefit is intervention for the child that will improve health outcomes.

Benefits, burdens \& consent processes

- Newborn screening programs exhibit near universal uptake, irrespective of consent approach.

Parental knowledge \& understanding: implications for consent approaches

- There is a lack of evidence regarding best-practice for the provision of information prior to the conduct of newborn screening.

Screening uptake \& perceptions of choice

- Newborn screening is often experienced as routine, even in jurisdictions operating under an informed consent mandate.

- Parents wish to be informed and consented with respect to secondary use of bloodspots for research.

Benefits, burdens \& individual decision-making

- More research is needed to better understand parental decision-making.

Where are we, what do we still need to learn \& why?

- Technological advances, such as whole-genome sequencing, will generate vastly increased amounts of data, and could compound these issues.

\section{References}

Papers of special note have been highlighted as:

- of interest; $\bullet$ of particular interest

1 Burton H, Moorthie S. Expanded newborn screening. A Review of the Evidence. PHG Foundation, Cambridge, UK (2010).

- Detailed review of expanded newborn screening, covering both the technical aspects as well as clinical implications and social and ethical issues.

2 Green NS, Dolan SM, Murray TH. Newborn screening: complexities in universal genetic testing. Am. J. Public Health 96(11), 1955-1959 (2006).

3 Padilla CD, Therrell BL. Newborn screening in the Asia Pacific region. J. Inherit. Metab. Dis. 30, 490-506 (2007).
4 Saadallah AA, Rashed MS. Newborn screening: experiences in the Middle East and North Africa. J. Inherit. Metab. Dis. 30(4), 482-489 (2007).

5 Bodamer OA, Hoffmann GF, Lindner M. Expanded newborn screening in Europe 2007. J. Inherit. Metab. Dis. 30, 439-444 (2007).

6 Burgard P, Rupp K, Lindner M et al. Newborn screening programmes in Europe; arguments and efforts regarding harmonization. Part 2. From screening laboratory results to treatment, follow-up and quality assurance. J. Inherit. Metab. Dis. 35(4), 613-625 (2012).

7 Therrell BL, Adams J. Newborn screening in North America. J. Inherit. Metab. Dis. 30, 447-465 (2007).

8 Borrajo GJC. Newborn screening in Latin America at the beginning of the 21st century. J. Inherit. Metab. Dis. 30, 466-481 (2007). 
9 Botkin JR, Goldenberg AJ, Rothwell E, Anderson RA, Lewis MH. Retention and research use of residual newborn screening bloodspots. Pediatrics 131, 1-8 (2012).

10 Koppaka R. Ten Great Public Health Achievements - United States, 2001-2010. MMWR Morb. Mortal. Wkly. Rep. 60(19), 619-623 (2011).

11 Raffle AE, Gray JaM. Screening: evidence and practice. Oxford University Press, Oxford, UK (2007).

- This book provides a historical account of screening, as well as definitions of screening and its limitations. The book also discusses the implementation and evaluation of screening programs, as well as screening policy.

12 Centerwall SA, Centerwall WR. The discovery of Phenylketonuria: The story of a young couple, two retarded children, and a scientist. Pediatrics 105(1), 89-103 (2000).

13 Pollitt RJ. Introducing new screens: why are we all doing different things? J. Inherit. Metab. Dis. 30, 423-429 (2007).

14 Arn PH. Newborn screening: current status. Health Aff. 26(2), 559-566 (2007).

15 Kaye CI, Accurso F, La Franchi S et al. Newborn screening fact sheets. Pediatrics 118(3), e934-e963 (2006).

16 Fowler DJ, Picker J, Waisbren SE, Levy HL. Neonatal screening for medium-chain acyl-CoA dehydrogenase deficiency. Lancet 359(9306), 628 (2002).

17 Watson MS, Lloyd-Puryear MA, Mann MY, Rinaldo P, Howell RR. Newborn screening: toward a uniform screening panel and system. Main report. Genet. Med. 8, 12S-252S (2006).

-. This report details the decisions, and decision-making process, of the American College of Medical Genetics (ACMG) that preceded the expansion of newborn screening programs in the US. A key text.

18 Botkin JR, Clayton EW, Fost NC et al. Newborn screening technology: proceed with caution. Pediatrics 117(5), 1793-1799 (2006).

- An informative critique of the American College of Medical Genetics and Genomics decision-making process that led to the expansion of newborn screening in the US.

19 Borte S, Von Dobeln U, Hammarstrom L. Guidelines for newborn screening of primary immunodeficiency diseases. Curr. Opin. Hematol. 20 (1), 48-54 (2013).

20 Scott CR, Elliott S, Buroker N et al. Identification of infants at risk for developing Fabry, Pompe, or mucopolysaccharidosis-I from newborn blood spots by tandem mass spectrometry. J. Pediatr. 163(2), 498-503 (2013).

21 Discretionary Advisory Committee on Heritable Disorders in Newborns and Children. Nominated Conditions. US Department of Health and Human Services. www.hrsa.gov/advisorycommittees/mchbadvisory/ heritabledisorders/nominatecondition/workgroup.html

22 Wion E, Brantley M, Stevens J et al. Population-wide infant screening for HLA-based type 1 diabetes risk via dried blood spots from the public health infrastructure. Ann. NY Acad. Sci. 1005, 400-403 (2003).
23 Hagopian WA, Erlich H, Lernmark A et al. The Environmental Determinants of Diabetes in the Young (TEDDY): genetic criteria and international diabetes risk screening of 421000 infants. Pediatr. Diabetes 12(8), 733-743 (2011).

24 Kerruish NJ. Parents' experiences of newborn screening for genetic susceptibility to type 1 diabetes. J. Med. Ethics 37(6), 348-353 (2011).

25 Kerruish NJ, Campbell-Stokes PL, Gray A, Merriman TR, Robertson SP, Taylor BJ. Maternal psychological reaction to newborn genetic screening for type 1 diabetes. Pediatrics 120(2), e324-e335 (2007).

26 Secretary's Advisory Committee on Heritable Disorders in Newborns and Children. Secretary's Advisory Committee on Heritable Disorders in Newborns and Children. 2013 Annual Report. US Department of Health and Human Services, Washington, DC, USA (2013).

27 Green A, Pollitt RJ. Population newborn screening for inherited metabolic disease: Current UK perspectives. J. Inherit. Metab. Dis. 22, 572-579 (1999).

28 Paul DB. Patient advocacy in newborn screening: continuities and discontinuities. Am. J. Med. Genet. C. Semin. Med. Genet. 148C(148C), 8-14 (2008).

29 Paul DB. Appendix 5: The history of newborn phenylketonuria screening in the US In: Promoting Safe and Effective Genetic Testing in the United States: Final Report of the Task Force on Genetic Testing., Holtzman NA, Watson MS (Eds). NIH, Bethesda, MD, USA, 137-160 (1997).

30 Bailey DB Jr, Armstrong FD, Kemper AR, Skinner D, Warren SF. Supporting family adaptation to presymptomatic and 'untreatable' conditions in an era of expanded newborn screening. J. Pediatr. Psychol. 34(6), 648-661 (2009).

31 Calonge N, Green NS, Rinaldo P et al. Committee report: Method for evaluating conditions nominated for populationbased screening of newborns and children. Genet. Med. 12(3), 153-159 (2010).

32 Andermann A. Revisting Wilson and Jungner in the genomic age: a review of screening criteria over the past 40 years. Bull. World Health Organ. 86(4), 317-319 (2008).

33 Petros M. Revisiting the Wilson-Jungner criteria: how can supplemental criteria guide public health in the era of genetic screening? Genet. Med. 14(1), 129-134 (2012).

34 Bailey DB Jr, Beskow LM, Davis AM, Skinner D. Changing perspectives on the benefits of newborn screening. Ment. Retard. Dev. Disabil. Res. Rev. 12(4), 270-279 (2006).

35 Buchbinder M, Timmermans S. Newborn screening and maternal diagnosis: rethinking family benefit. Soc. Sci. Med. 73(7), 1014-1018 (2011).

36 Metcalfe SA, Archibald AD, Atkinson A et al. Conflicting views on newborn and infant genetic screening: perspectives of relatives of children with genetic conditions causing developmental delay and parents of healthy children. Abstracts of the American Society of Human Genetics annual conference. San Francisco, CA, USA, 6-8 November 2012.

37 Botkin JR. Assessing the new criteria for newborn screening. Health Matrix 19(16), 163-186 (2009). 
38 Grosse SD, Boyle CA, Kenneson A, Khoury MJ, Wilfond BS. From public health emergency to public health service: the implications of evolving criteria for newborn screening panels. Pediatrics 117(3), 923-929 (2006).

39 Almond B. Genetic profiling of newborns: ethical and social issues. Nat. Rev. Genet. 7, 67-71 (2005).

40 Potter BK, Avard D, Entwistle V et al. Ethical, legal, and social issues in health technology assessment for prenatal/ preconceptional and newborn screening: a workshop report. Public Health Genomics 12(1), 4-10 (2009).

41 Castellani C, Southern KW, Brownlee K et al. European best practice guidelines for cystic fibrosis neonatal screening. J. Cyst. Fibros. 8(3), 153-173 (2009).

42 Godard B, Ten Kate L, Evers-Kiebooms G, Ayme S. Population genetic screening programmes: principles, techniques, practices, and policies. Eur. J. Hum. Genet. 11(Suppl. 2), S49-S87 (2003).

43 Bombard Y, Miller FA. Reply to Ross' commentary: Reproductive benefit through newborn screening: preferences, policy and ethics. Eur. J. Hum. Genet. 20, 486-489 (2012).

44 Bombard Y, Miller FA, Hayeems RZ et al. Health-care providers' views on pursuing reproductive benefit through newborn screening: the case of sickle cell disorders. Eur. J. Hum. Genet. 20 (5), 498-504 (2012).

45 Bradley DM, Parsons EP, Clarke AJ. Experience with screening newborns for Duchenne muscular dystrophy in Wales. Br. Med. J. 306(6874), 357-360 (1993).

46 Ross LF. Newborn screening for sickle cell disease: whose reproductive benefit? Eur. J. Hum. Genet. 20(5), 484-485 (2012).

47 Laird L, Dezateux C, Anionwu EN. Neonatal screening for sickle cell disorders: what about the carrier infants? Br. Med. J. 313, 407-411 (1996).

48 Ross LF. Predictive genetic testing for conditions that present in childhood. Kennedy. Inst. Ethics. J. 12(3), 225-244 (2002).

49 Hayeems RZ, Bytautas JP, Miller FA. A systematic review of the effects of disclosing carrier results generated through newborn screening. J. Genet. Couns. 17(6), 538-549 (2008).

50 Ross LF. Newborn screening for conditions that do not meet the Wilson and Jungner criteria. The case of duchenne muscular dystrophy. In: Ethics and Newborn Genetic Screening. New Technologies, New Challenges. Baily MA, Murray TH (Eds). The Johns Hopkins University Press, Baltimore, MD, USA (2009).

51 Kohane IS, Masys DR, Altman RB. The incidentalome. JAMA 196(2), 212-215 (2006).

- Highly accessible and informative paper that discusses the implications of expanded testing and particularly statistical considerations.

52 Juth N, Munthe C. The Ethics of Screening in Healthcare and Medicine. Serving Society or Serving the Patient? Springer, Dordrecht, The Netherlands (2012).

53 Tarini BA, Goldenberg AJ. Ethical issues with newborn screening in the genomics era. Annu. Rev. Genom. Hum. Genet. 13, 381-393 (2012).
54 Ross LF. Mandatory versus voluntary consent for newborn screening? Kennedy. Inst. Ethics. J. 20(4), 299-328 (2010).

55 Dees RH, Kwon JM. The Ethics of Krabbe Newborn Screening. Public Health Ethics 6(1), 114-128 (2012).

- Lead article discussing issues of of screening when the natural history of the condition is not well defined and potential for overdiagnosis.

56 Miller FA. The sad story of newborn screening for Krabbe: the need for good governance. Public Health Ethics 6(1), 123-126 (2013).

57 Ross LF. Newborn screening for Krabbe disease: what Illinois can learn from New York. Public Health Ethics 6(1), 119-123 (2013).

58 Ross LF. Newborn screening for lysosomal storage diseases: an ethical and policy analysis. J. Inherit. Metab. Dis. 35(4), 627-634 (2012).

59 The President's Council on Bioethics. The Changing Moral Focus of Newborn Screening: An Ethical Analysis by the President's Council on Bioethics. The President's Council on Bioethics, Washington, DC, USA (2008).

60 Wilson JMG, Jungner G. Principles and Practice of Screening for Disease. World Health Organization, Geneva, Switzerland (1968).

61 Campbell E, Ross LF. Parental attitudes regarding newborn screening of PKU and DMD. Am. J. Med. Genet. 120A(120A), 209-214 (2003).

62 Detmar S, Dijkstra N, Nijsingh N, Rijnders M, Verweij M, Hosli E. Parental opinions about the expansion of the neonatal screening programme. Community Genet. 11, 11-17 (2008).

63 Lipstein EA, Nabi E, Perrin JM, Luff D, Browning MF, Kuhlthau KA. Parents' decision-making in newborn screening: opinions, choices, and information needs. Pediatrics 126(4), 696-704 (2010).

64 Hasegawa LE, Fergus KA, Ojeda N, Au SM. Parental attitudes toward ethical and social issues surrounding the expansion of newborn screening using new technologies. Public Health Genomics 14(4-5), 298-306 (2010).

65 Etchegary H, Dicks E, Green J, Hodgkinson K, Pullman $\mathrm{D}$, Parfrey P. Interest in newborn genetic testing: a survey of prospective parents and the general public. Genet. Test. Mol. Biomarkers 16(5), 353-358 (2012).

66 Hayeems RZ, Miller FA, Bombard Y et al. Expectations and values about expanded newborn screening: a public engagement study. Health Expect. doi:10.1111/hex.12047 (2013) (Epub ahead of print).

67 Muchamore I, Morphett L, Barlow-Stewart K. Exploring existing and deliberated community perspectives of newborn screening: informing the development of state and national policy standards in newborn screening and the use of dried blood spots. Aust. New Zealand Health Policy 3, 14 (2006).

68 Plass AM, Van El CG, Pieters T, Cornel MC. Neonatal screening for treatable and untreatable disorders: prospective parents' opinions. Pediatrics 125(1), e99-e106 (2010).

69 Quinlivan JA, Suriadi C. Attitudes of new mothers towards genetics and newborn screening. J. Psychosom. Obstet. Gynaecol. 27(1), 67-72 (2006). 
70 Weinreich SS, Rigter T, Van El CG et al. Public support for neonatal screening for Pompe disease, a broad-phenotype condition. Orphanet. J. Rare Dis. 7, 15 (2012).

71 Etchegary H, Dicks E, Hodgkinson K, Pullman D, Green J, Parfey P. Public attitudes about genetic testing in the newborn period. J. Obstet. Gynecol. Neonatal Nurs. 41(2), 191-200 (2012).

72 Nicholls SG, Southern KW. Parental decision-making and acceptance of newborn bloodspot screening: an exploratory study. PLoS ONE 8(11), e79441 (2013).

73 Grob R. Is my sick child healthy? Is my healthy child sick?: changing parental experiences of cystic fibrosis in the age of expanded newborn screening. Soc. Sci. Med. 67(7), 1056-1064 (2008).

74 Gurian EA, Kinnamon DD, Henry JJ, Waisbren SE. Expanded newborn screening for biochemical disorders: the effect of a false-positive result. Pediatrics 117(6), 1915-1921 (2006).

75 Waisbren SE, Albers S, Amato S et al. Effect of expanded newborn screening for biochemical genetic disorders on child outcomes and parental stress. JAMA 290, 2564-2572 (2003).

76 Hewlett J, Waisbren SE. A review of the psychosocial effects of false-positive results on parents and current communication practices in newborn screening. J. Inherit. Metab. Dis. 29(5), 677-682 (2006).

77 Grob R. Parenting in the genomic age: the 'cursed blessing' of newborn screening. New Genet. Soc. 25(2), 159-170 (2006).

78 Buchbinder M, Timmermans S. Newborn screening for metabolic disorders: parental perceptions of the initial communication of results. Clin. Pediatr. 51(8), 739-744 (2012).

79 Tarini BA, Christakis DA, Welch HG. State newborn screening in the tandem mass spectrometry era: more tests, more false-positive results. Pediatrics 118(2), 448-456 (2006).

80 Thelin T, Mcneil TF, Aspegren-Jansson E, Sveger T. Psychological consequences of neonatal screening for alpha-1 antitrypsin deficiency (ATD). Parental attitudes toward 'ATD-Check-ups' and parental recommendations regarding future screening. Acta Paediatr. Scand. 74, 841-847 (1985).

81 Goldstein E, Hermann R, Renfors TJ et al. From genetic risk awareness to overt Type 1 diabetes: parental stress in a placebo-controlled prevention trial. Diabetes Care 32(12), 2181-2183 (2009).

82 Lewis S, Curnow L, Ross M, Massie J. Parental attitudes to the identification of their infants as carriers of cystic fibrosis by newborn screening. J. Paediatr. Child Health 42(9), 533-537 (2006).

83 Schmidt JL, Castellanos-Brown K, Childress S et al. The impact of false-positive newborn screening results on families: a qualitative study. Genet. Med. 14(1), 76-80 (2012).

84 Tluczek A, Koscik RL, Farrell PM, Rock MJ. Psychosocial risk associated with newborn screening for cystic fibrosis: parents' experience while awaiting the sweat-test appointment. Pediatrics 115(6), 1692-1703 (2005).
85 Nicholls SG, Southern KW. Parental information use in the context of newborn bloodspot screening. An exploratory mixed methods study. J. Community Genet. 3(4), 251-257 (2012).

86 Davis TC, Humiston SG, Arnold CL et al. Recommendations for effective newborn screening communication: results of focus groups with parents, providers, and experts. Pediatrics 117(5 Pt 2), S326-S340 (2006).

87 Detmar S, Hosli E, Dijkstra N, Nijsingh N, Rijnders M, Verweij M. Information and informed consent for neonatal screening: opinions and preferences of parents. Birth 34(3), 238-244 (2007).

88 Campbell ED, Ross LF. Incorporating newborn screening into prenatal care. Am. J. Obstet. Gynecol. 190 (4), 876-877 (2004).

89 Timmermans S, Buchbinder M. Patients-in-waiting: Living between sickness and health in the genomics era. J. Health Soc. Behav. 51(4), 408-423 (2010).

90 Timmermans S, Buchbinder M. Saving Babies? The Consequences of Newborn Genetic Screening. The University of Chicago Press, Chicago, IL, USA (2013).

91 Bailey DB Jr, Skinner D, Davis AM, Whitmarsh I, Powell C. Ethical, legal, and social concerns about expanded newborn screening: fragile $\mathrm{X}$ syndrome as a prototype for emerging issues. Pediatrics 121(3), e693-e704 (2008).

92 Tluczek A, Orland KM, Nick SW, Brown RL. Newborn screening: an appeal for improved parent education. J. Perinat. Neonatal Nurs. 23(4), 326-334 (2009).

93 Laing IA, Mcintosh N. Practicalities of consent. Lancet 364(9435), 659 (2004).

94 Acharya K, Ackerman PD, Ross LF. Pediatricians' attitudes toward expanding newborn screening. Pediatrics 116(4), e476-e484 (2005).

95 Hiraki S, Ormond KE, Kim K, Ross LF. Attitudes of genetic counselors towards expanding newborn screening and offering predictive genetic testing to children. Am. J. Med. Genet. Part A 140 (21), 2312-2319 (2006).

96 Kemper AR, Wake MA. Duchenne muscular dystrophy: issues in expanding newborn screening. Curr. Opin. Pediatr. 19, 700-704 (2007).

97 Wilcken B. Ethical issues in newborn screening and the impact of new technologies. Eur. J. Pediatr. 162, S62-S66 (2003).

98 Therrell BL, Johnson A, Williams D. Status of newborn screening programs in the United States. Pediatrics 117(5 Pt 2), S212-S252 (2006).

99 Ross LF, Saal HM, David KL, Anderson RR, And the American Academy of Pediatrics, American College of Medical Genetics and Genomics. Technical report: ethical and policy issues in genetic testing and screening of children. Genet. Med. 15(3), 234-245 (2013).

100 Committee on Bioethics, Committee on Genetics, The American College of Medical Genetics and Genomics Social EaLIC. Ethical and policy issues in genetic testing and screening of children. Pediatrics 131(3), 620-622 (2013). 
101 Schweers RL. Newborn screening programs: how do we best protect privacy rights while ensuring optimal newborn health? DePaul L. Rev. 61 (2012).

102 Foral FE. Necessity's sharp pinch: parental and states' rights in conflict in an era of newborn genetic screening. J. Health Biomed. L. 11(1), 109-128 (2006).

103 Uk Newborn Screening Programme Centre. Guidelines for Newborn Blood Spot Sampling. UK Newborn Screening Programme Centre, London, UK (2008).

104 Araia MH, Wilson BJ, Chakraborty P et al. Factors associated with knowledge of and satisfaction with newborn screening education: a survey of mothers. Genet. Med. 14, 963-970 (2012).

105 Hanley WB. Newborn screening in Canada - are we out of step? Paediatr. Child Health 10(4), 203-207 (2005).

106 Miller FA, Hayeems RZ, Carroll JC et al. Consent for newborn screening: the attitudes of healthcare providers. Public Health Genomics 13(3), 181-190 (2010).

107 Dhondt JL. Implementation of informed consent for a cystic fibrosis newborn screening program in France: low refusal rates for optional testing. J. Pediatr. 147(Suppl. 3), S106-S108 (2005).

108 Faden R, Chwalow AJ, Holtzman NA, Horn SD. A survey to evaluate parental consent as public policy for neonatal screening. Am. J. Public Health 72, 1347-1352 (1982).

109 Annas GJ. Mandatory PKU screening: The other side of the looking glass. Am. J. Public Health 72, 1401-1403 (1982).

110 Nicholls SG, Southern KW. Considering consent: a structural equation modelling analysis of factors influencing decisional quality when accepting newborn screening. J. Inherit. Metab. Dis. 37, 197-205 (2014).

- One of few studies to explore individual parent decisionmaking. It is unique in its application of quantitative approaches to modeling decision-making for newborn screening.

111 Clarke A. Newborn screening. In: Genetics, Society and Clinical Practice. Harper PS, Clarke A (Eds). Bios, Oxford, UK (1997).

112 Murray A, Clarke A. The ethics of population screening. Curr. Paediatr. 12, 447-452 (2002).

113 Nicholls SG, Southern KW. Informed choice for newborn blood spot screening in the United kingdom: a survey of parental perceptions. Pediatrics 130(6), e1527-e1533 (2012).

114 Hargreaves K, Stewart R, Oliver S. Informed choice and public health screening for children: the case of blood spot screening. Health Expect. 8, 161-171 (2005).

115 Parsons EP, King JT, Israel JA, Bradley DM. Mothers' accounts of screening newborn babies in Wales (UK). Midwifery 23(1), 59-65 (2007).

116 Newcomb P, True B, Walsh J, Dyson M, Lockwood S, Douglas B. Maternal attitudes and knowledge about newborn screening. MCN Am. J. Matern. Child Nurs. 38(5), 289-294 (2013).

117 Deluca JM, Kearney MH, Norton SA, Arnold GL. Parents' experiences of expanded newborn screening evaluations. Pediatrics 128(1), 53-61 (2011).
118 Smith RA, Williams DK, Sibert JR, Harper PS. Attitudes of mothers to neonatal screening for Duchenne muscular dystrophy. Br. Med. J. 300, 1112 (1990).

119 Tluczek A, Mischler EH, Farrell PM et al. Parents' knowledge of neonatal screening and response to false-positive cystic fibrosis testing. J. Dev. Behav. Pediatr. 13, 181-186 (1992).

120 Suriadi C, Jovanovska M, Quinlivan JA. Factors affecting mothers' knowledge of genetic screening. Aust. NZ J. Obstet. Gynaecol. 44, 30-34 (2004).

121 Nicholls SG. Knowledge or understanding? Informed choice in the context of newborn bloodspot screening. Public Health Ethics 3(2), 128-136 (2010).

122 Warren NS, Carter TP, Humbert JR, Rowley PT. Newborn screening for hemoglobinopathies in New York state: experience of physicians and parents of affected children. J. Pediatr. 100, 373-377 (1982).

123 Uk Newborn Screening Programme Centre. Guidelines for Newborn Blood Spot Sampling. UK National Screening Committee, London, UK (2012).

124 Moran J, Quirk K, Duff AJA, Brownlee KG. Newborn screening for $\mathrm{CF}$ in a regional paediatric centre: The psychosocial effects of false-positive IRT results on parents. J. Cyst. Fibros. 6, 250-254 (2007).

125 Parsons EP, Moore C, Israel J, Hood K, Clarke AJ, Bradley DM. Emphasizing parental choice on newborn screening. Br. J. Midwifery 13, 165-168 (2005).

126 Nicholls SG. Proceduralisation, choice and parental reflections on decisions to accept newborn bloodspot screening. J. Med. Ethics 38, 299-303 (2012).

127 Tymstra T. False positive results in screening tests: Experiences of aprents of children screened for congenital hypothyroidism. Fam. Pract. 3(2), 92-96 (1986).

128 Muchamore I, Morphett L, Barlow-Stewart K. Community Views and Perspectives of Newborn Screening. The Centre for Genetics Education, Sydney, Australia (2006).

129 Couzin-Frankel J. Science gold mine, ethical mindefield. Science 324, 166-168 (2009).

130 Douglas C, Van El C, Radstake M, Van Teeffelen S, Cornel $\mathrm{MC}$. The politics of representation in the governance of emergent 'secondary use' biobanks: the case of dried blood spot cards in The Netherlands. Stud. Ethics Law. Technol. 6(1), Article 4 (2012).

131 Bombard Y, Miller FA, Hayeems RZ et al. Citizens' values regarding research with stored samples from newborn screening in Canada. Pediatrics 129, 239-247 (2012).

132 Lewis MH, Scheurer ME, Green RC, McGuire AL. Research results: Preserving newborn blood samples. Sci. Transl. Med. 4(159), 1-3 (2012).

133 Armstrong J. Storage of newborns' blood samples raises privacy concerns Globe and Mail. www.theglobeandmail.com/news/british-columbia/ storage-of-newborns-blood-samples-raises-privacy-concerns/ article 4318768

134 Davey A, French D, Dawkins H, O’Leary P. New mothers awareness of newborn screening, and their attitudes to the retention and use of screening samples for resarch purposes. Genomics Society Policy 1(3), 41-51 (2006). 
135 Gustafsson Stolt U, Liss P-E, Svensson T, Ludvigsson J. Attitudes to bioethical issues: a case study of a screenig project. Soc. Sci. Med. 54, 1333-1344 (2002).

136 Botkin JR, Rothwell E, Anderson R et al. Public attitudes regarding the use of residual newborn screening specimens for research. Pediatrics 129(2), 231-238 (2012).

137 Parsons EP, Israel J, Hood K, Bradley DM. Optional screening for DMD: reasons given by mothers for optin in or out. Br. J. Midwifery 14(12), 710-714 (2006).

138 Parsons EP. Newborn screening for Duchenne muscular dystrophy: a psychosocial study. Arch. Dis. Child. Fetal Neonatal Ed. 86(2), 91-95 (2002).

139 Simpson N, Randall R, Lenton S, Walker S. Audit of neonatal screening programme for phenylketonuria and congenital hypothyroidism. Arch. Dis. Child. Fetal Neonatal Ed. 77, F228-F234 (1997).

140 Milburn J, Marcadier J, Rogers I et al. Alerts of potential missed screens in Ontario, Canada. Presented at: 8th ISNS European Meeting. Budapest, Hungary, 4-6 November 2012.

141 Hayeems RZ, Miller FA, Little J et al. Informing parents about expanded newborn screening: influences on provider involvement. Pediatrics 124(3), 950-958 (2009).

142 Press N, Clayton EW. Genetics and public health: Informed consent beyond the clinical encounter. In: Genetics and Public Health in the 21st Century. Khoury MJ, Burke W, Thomson EJ (Eds). Oxford, NY, USA, 505-526 (2000).

143 Kemper AR, Green NS, Calonge N et al. Decision-making process for conditions nominated to the Recommended
Uniform Screening Panel: statement of the US Department of Health and Human Services Secretary's Advisory Committee on Heritable Disorders in Newborns and Children. Genet. Med. 16(2), 183-187 (2014).

144 Prasad V, Ioannidis JPA. Evidence-based de-implentation for contradicted, unproven, and aspiring healthcare practices. Implement. Sci. 9, 1 (2007).

145 Nijsingh N. Krabbe Newborn screening: the issue of informed consent. Public Health Ethics 6(1), 126-128 (2013).

146 Goldenberg AJ, Dodson DS, Davis MM, Tarini BA. Parents' interest in whole-genome sequencing of newborns. Genet. Med. 16(1), 78-84 (2013).

147 Goldenberg AJ, Sharp RR. The ethical hazards and programmatic challenges of genomic newborn screening. JAMA 307(5), 461-462 (2012).

148 Haga SB. Ethical issues of predictive genetic testing for diabetes. J. Diabetes Sci. Technol. 3(4), 781-788 (2009).

149 Dewey FE, Grove ME, Pan C et al. Clinical Interpretation and Implications of Whole-Genome Sequencing. JAMA 311(10), 1035 (2014).

150 Feero WG. Clinical application of whole-genome sequencing. Proceed with care. JAMA 311(10), 1017-1019 (2014).

151 Li C. Personalized medicine - the promised land: are we there yet? Clin. Genet. 79(5), 403-412 (2011).

152 Berg JS, Khoury MJ, Evans JP. Deploying whole-genome sequencing in clinical practice and public health: meeting the challenge one bin at a time. Genet. Med. 13(6), 499-504 (2011). 